Prnted in the United Staten of America Avalablo trom National Techaical Information Service

U S Department of Commerce

5285 Port Royal Road

Springtield, VA 22151

Price Printed Copy \$1.00 Microfiche $\$ 2.25$

This report wal gregared an an accrount of work spontroted bi the l'niled Silates fiovernment. Neither the I nuled Stales.

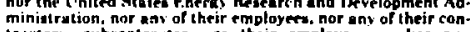
irwetors. aubcontructors or their emplasers. makee an

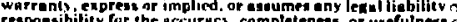
ant information apouratus, product or prorent duslosed.

repantents that ite use would not infringe brivalely owned
righis. 


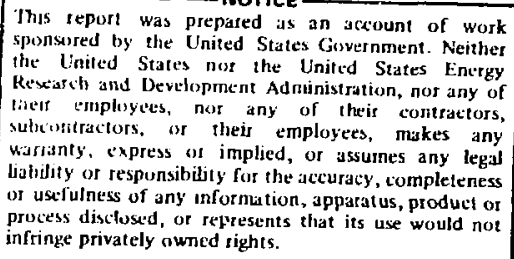

\title{
NEUTRON SPECTRUM FROM AN ORALLOY SPHERE
}

\author{
by
}

Charles F. Ragan, George F. Auchampaugh, Arthur Hemmendinger, and Myron G. Silbert

\begin{abstract}
The neutron spectrum from a $38-\mathrm{kg}$ oralloy sphere, pulsed by a centrally located 14-MeV neutron source, has been measured using time-of-flight (TOF) techniques. The nearly isotropic source of 14$\mathrm{MeV}$ neutrons was produced by bombarding a tritium gas target with low-energy deuterons. Neutrons in the 0.180 - to $15.0-\mathrm{MeV}$ energy range were detected at the end of a partially evacuated, 39m flight path by a NE-213 liquid scintillator that used pulse shape discrimination to distinguish neutron events from gamma-ray events. Detector thresholds of 0.15 and $0.85 \mathrm{MeV}$ were used to cover the above energy range, and the detector efficiency was ineasured over this range using monoenergetic neutrons from the $T(p, n)$, $T(d, n)$, and $D(d, n)$ reacions. Several measurements of the TOF spectrum were used to determine the neutron flux at the detector, and a comparison of this flux with the results of Monte Carlo calculations is presented. These calculations were performed with the code MCN using two cross-section sets, those from the Lawrence Livermore Laboratory (LLL) and those from the ENDF/B-IV library. The results calculated using the ENDF/B-IV cross sections are in excellent agreement with the measurements, especially in the 1- to 6-MeV energy region, where the uncertainties in both the calculated and experimental results are the smallest.
\end{abstract}

\section{INTRODUCTION}

The Las Alamos Seientific I aboratory's IlASil. Theoretical Design Division has requested measurements of fission densicies as a function of position in various assemblies. ' These measurements will be used as benchmarks in evaluating Monte Carlo calculations, and the com. clusions should be widely applicable. Common to each assembly mentioned above is a hollow $38-\mathrm{kg}$ oralloy $(93.5 \%, 231,6.5 \%, 234(1)$ sphere which will be the component directly surrounding an approximately isotropie source of $14-\mathrm{MeV}$ neutrons. Knowledge of the neut ron enetgy spect rum from this sphere is necessary to make accurate calculations of finsion densities in the specified assemblies. Therefore. as a first step in this program. a measurement of this spectrum was underraken. and a preliminary report" on this measurement was prepared for the Theoretical Design Division.

\section{ACCELERA'TOK}

Several accelerator: capable of producing nearly isot ropic pulses of $14-\mathrm{MeV}$ neutrons exist at LASI. These accelerators are basicaliy of two types: Cockeroft-Wilton accelerators which produce 14 MeY neut rons from the $T(d . n)$ reaction using $330(i-10$ tho-keV deuterons and $V$ in de Graaff accelerators 
capable of producing neut rons with a widt range of energies from various reactions. At a pulse rate of :3.5 $\mathrm{MHz}$, one Cockcroft-Walton accelerator is capahle of producing $\sim 5 \times 10^{8}$ neutrons/s using a solid tritium-zirconium target, whereas the Van de Graiff accelerators are capable of producing about $10^{4}$ neutrons/s from the $T(d, n)$ reaction at approximately this same pulse rate using a tritium gas target. From this standpoint, neither machine has an obvious advantage. High-resolution neutron time-ofthight (TOF) measurements require accurate timing $(<1 \mathrm{~ns})$ over a wide time interval. These re. quirements dictate the use of fast. sophisticated electronics for digitizing the data and the use of an on-line computer for data storage. Only the Van de Graaff accelerators in LASL's Group P-9 are equipped in this manner; therefore, they were chosen for the TOF measurements.

The two Van de Graaff accelerators, at P-9 are a vertical. single-ended machine capable of providing 1. to 6-Mel deuterons and a tandem FN acceleratur capable of providing 4- to 18 - MeV deuterons. As the deuteron energy is increased above $110 \mathrm{keV}$. the rield from the $T(d, n)$ reaction decreases substantialIy. the neutron energy spread increases. and the degree of isotropy decreases. Consequently. the deuterons from either P-9 machine inust be reduced in energy before interacting with the tritium. This can be accomplished by using an ent rance foil to the gas target of the appripriate thickness.

The deuterons from the vertical accelerator need " $"$ be degrided in energy only slightly, thereby raquiring a much thinner foil with less cnersy straggling. This machine, however, has several unfavorable features, 11) The energy resolution obtainable in rof depends upon the length of the flight path. When this experiment was being planned. the construction of a 40 -m thight path was under way at the tandem. and there were no provisions for a thight path of this length on the vertical. (2) Todet eet lin. energy neutrons, the time between pulses must be such that these neutrons can reach the detector hefore high-energy neutrons arrive from the next heam pulse. The pulse rate at the vertical machine is essentially fixed at $2.0 \mathrm{MHz}$, whereas the pulse rate on the tandem can be decreased in sleps of two from $2.5 \mathrm{MHz}$ to $78.125 \mathrm{kHz}$. Therefore the tanclem accelerator was chosen for the spectrum measurements, with the accepted disadvantage of more straggling in the entrance fosil to the gas cell.

At the higher heam energies necessary on the tandem, a larger hackground of noutrons was produced in the entrance foil. This backgrourid decreased substantially with decreasing energy, but so did the beam current. At a beam energy of $4 \mathrm{MeV}$. the available current was down by mure than an order of magnitude from the maximum. Thus, the choice of the beam energr was a trade.nff between beam current and background, wit h the exact energy determined hy the entrance foil thickness.

After selecting the facility, it was necessary to complete the installation of the llight tube, install the target and tritium gas handling s'stem. determine the characteristics of the neutron source. instail a detector system at the end of the flight tube. and construct a support for the oralloy sphere. The details of this work are described in the following sections.

\section{NEUTRON SOURCE}

Fur a thin target, the peak cross section ${ }^{3-3}$ for the Tid,n) reaction uccurs at approximately $110 \mathrm{keV}$. At this energy. the angular dist ribut ion of neut rons can be calculated from the reaction 'inematics, assuning an isotropic distribution in the center of mass. However. when a llick entrance windew and target are used. the angular dist ribut ion needs to be determined cxperiment ally.

Measurements of the soure characteristics were performed on the R-y beam les of the tandem accolerator. Figure 1 show's the experimenta! setup. The detecter system was the sime as used tor the spectrum measurements, with the low-energy threshold set at approximately 0.8i Mel. The detector and shield were placed on a cart that rotited about the center of the gas cedl (Fig. 2). The pressure seal for the gas cell consisied of two indium gaskets and a molybdenum foil. The cell was filled through the 1.1-mm-diam hypodermic tubing and was insulated from the beam tube and from the gas handling apparatus to allow current integration.

Measurements were made at a tritium pressure of 0.2()4 MPa gauge (30) psig) using molybdenum entrance foils of $t w 0$ (hicknesses--50 and $6.3 .5 \mu \mathrm{m}$. These thicknesses correspond 10 the range of $\mathbf{4 . 6}$ a.1 $5.3-\mathrm{M} \times \mathrm{V}$ deuterons: in molybdenum, respectively. Figure 3 shows the measured neut rom vield from the $T(d, n)$ reaction as a function of bombarding energy at $90^{\circ}$ to the beam for these two foils. The peak in the vield is caused by the $110 \mathrm{ke}-\mathrm{l}$ resthatice in the T(d.n) rass section. At boam energies below the peak. the transmitted deuterons are below tho resonance, and at beam energies above the mak. the deuterons do not lose sufficient energy in tho t ritium to reach the resoluance from above. Most of the neutrons at the peak of the vielal are theredore.

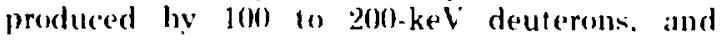




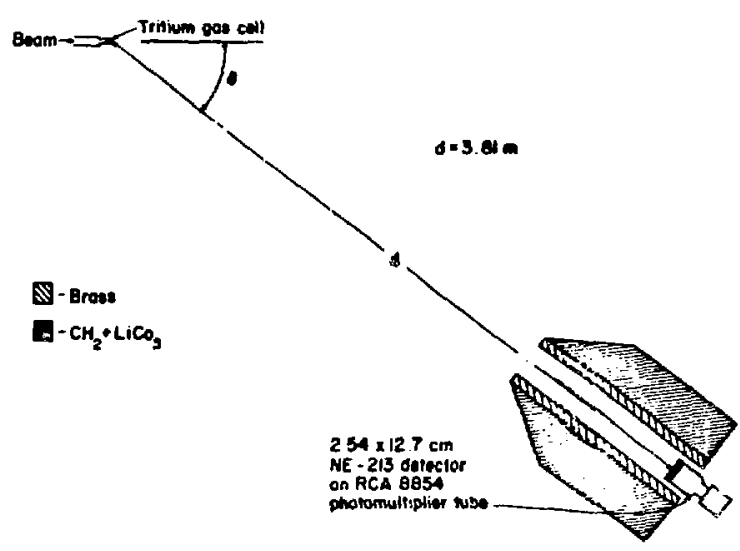

Fig. 1.

Experimental setup used for determining the ('nergy and yield as a furction of angie ( $\theta$ ) for the I-MeV neutron source. The neutrons were drtected with a shielded NE-213 detector mossuted in an RCA-8R54 photomultiplier tube placed $3.81 \mathrm{~m}$ from the source. The angle $\theta$ iaried from of ti) $1.35^{\circ}$.

calculations indicate that the average deuteron energy is approximately $150 \mathrm{keV}$.

Typical TOF spectra recorded at 0 and $90^{\circ}$ to the beam are shown in Fiy. 4. and the Tr(d.n) neutrons are seen to be well separated from the backursiund. The vield from the $T(d, n)$ reaction varied only slightly with angle. However, the vield of the background neutrons was extremely forward peaked. Tle angular distributions of the neutrons in the background at incident beam energies of 5.05 and i.ti $\mathrm{MeV}$, corresponding to the peak vields, are shown in

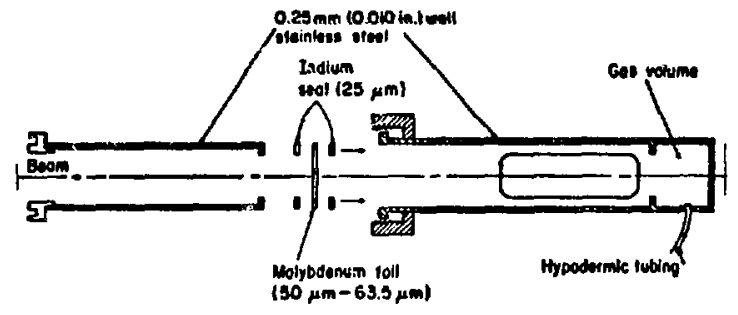

Fig. 2.

Exploded view of the tritium gas target assicmbly used as a source of $14-\mathrm{MeV}$ neutrons from the $T(d, n)$ reaction. The deuteron beam inters from the left and passes through the molvbdenum foil before entering the gas. The foil is sealed between the two sets of flanges by' the indium gaskets.

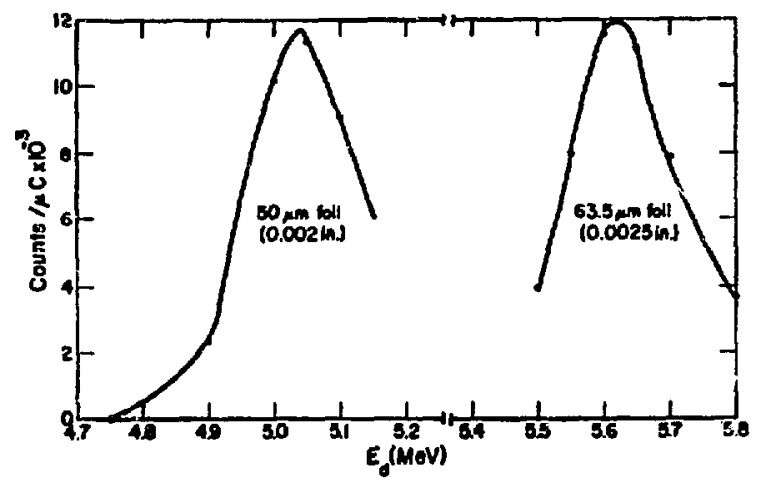

Fig. 3.

Plots of the counts per microcoulomb in the 14 .

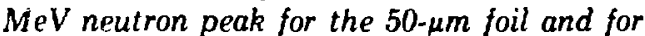

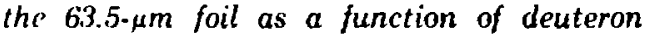
energy. The solid line is drawn to guide the eye. The vield is about the same for the two foils and the peak yields occur at about 5.05 and 5.60) $\mathrm{MeV}$ for the 50- and 63.5-um foils, respectively.

Fig. 5. These yields are plotted in counts per microcoulomb without correction for the detector efficiency to indicate the manner in which the yield changes with angle. The integrated background at

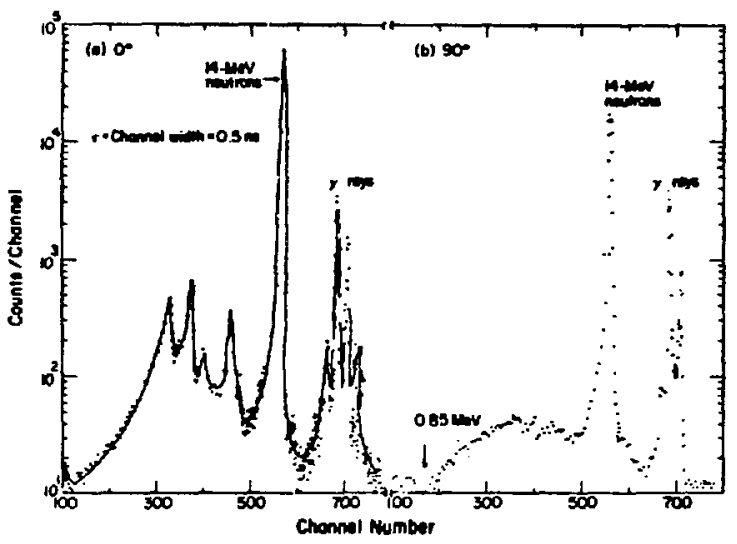

Fig. 4

Simple spectra obtained using the experimenial setup shoun in Fig. I at a bombarding imergy of $5.05 \mathrm{McV}$ with a 50 - $\mu \mathrm{m}$-thick foil. Buth spectra were recorded using 0.5-ns chamnel widths. Spectrum (a) was recorded with the detector at $0^{\circ}$ to the beam and the buckiground is much larger than in (b), which was recorded with the detector at $90^{\circ}$. 


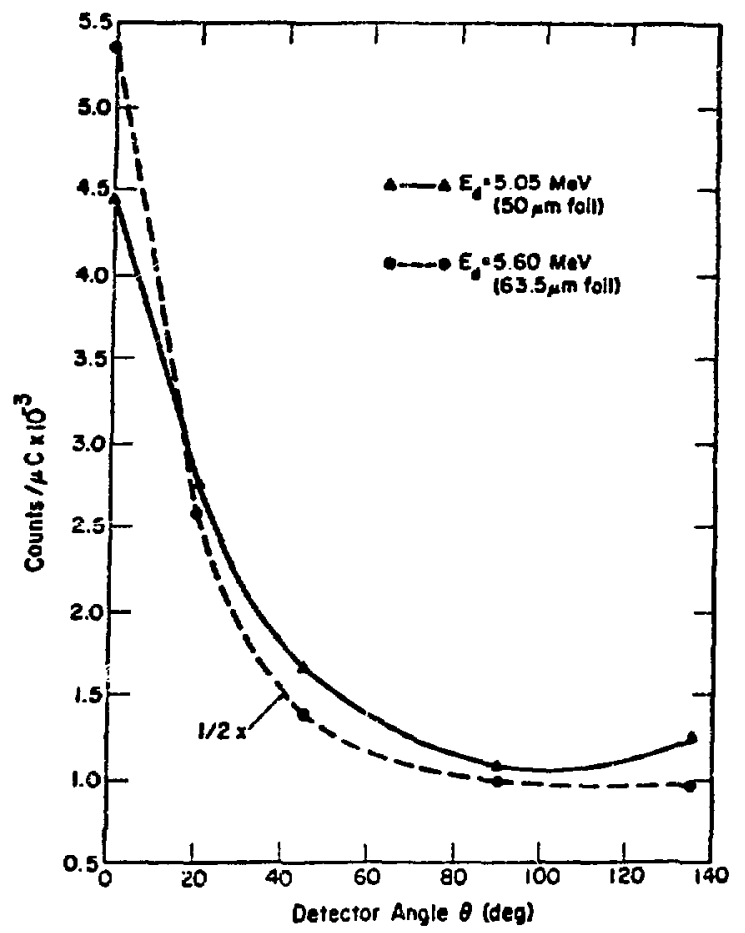

Fig. 5 .

Plots in counts per microcoulomb of the angular distribution of background neutrons. obtained with tuo foil thicknesses and beam chersies. The data obtained at a deuteron

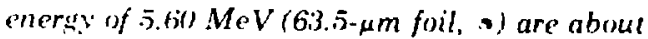
a factor of tw' higher than the data ubtained at a beam enersin of $.5 .05 \mathrm{M}, \mathrm{V}$ (.50 $\mathrm{\mu m}$ foil. $\wedge$ ).

$5.6 \mathrm{MeV}$ is larger than that at $5.05 \mathrm{MeV}$ hy approximately a factor of two. Thus, a $50-\mu \mathrm{m}$ entrance window and a 5.05-MeV beam eneryy were chusen for the spectrum measurements. $A:$ this beam energy the integrated hackground yield is $6^{\circ}$, of the integrated vield of neutrons from the Tid.n) reac. tion.

Figure 6 shows plots of the measiured $(\bullet)$ and calculated ( $\Delta$ ) energy and vield as a function of angle for neutrons from the $T(d . n)$ reaction at a deuteron energy of i.05 $\mathrm{MeV}$, corresponding to the neak of the yield curve for the $50-\mu \mathrm{m}$ molybdenum firil. The energy and vield were calculated from the reaction kinematics for a deuteron energy of $150 \mathrm{keV}$, and for the vield calculations an isotropic dist ribution in the

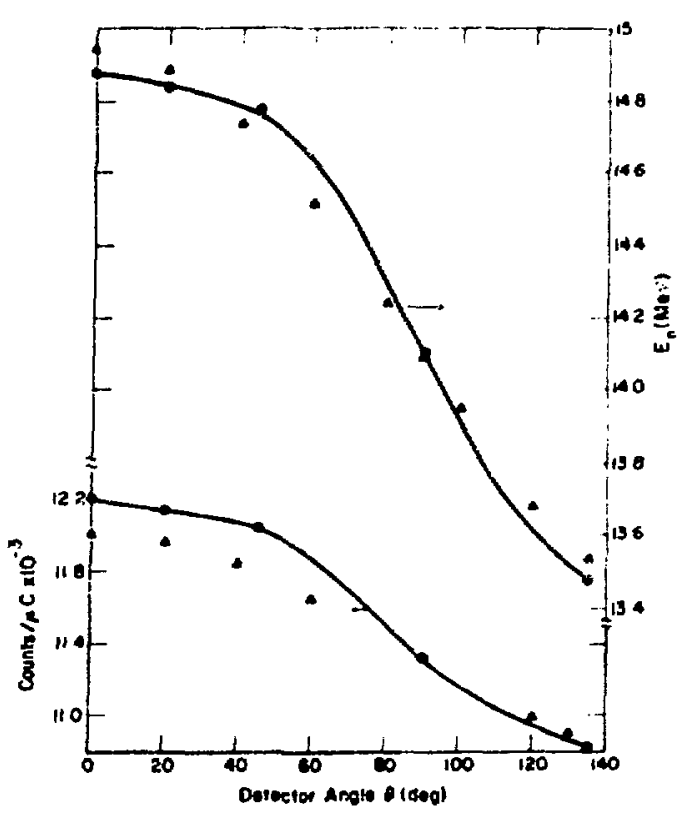

Fis. is.

Jyts of the cariatom of emersy (uppers and

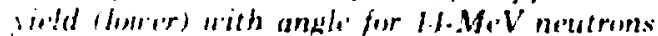
from the Thant reaction at an effective'

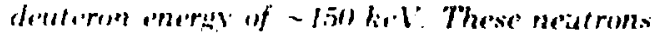
"ere prodeserd by .5 t.5-Mol' deaterons incidene

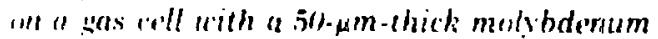
entrance foil. The a se represent the ealues culeulated from the reaction kinematies rsor (19l) and are in sind asresment with the mersured (e) eralues. The lines are drann to suide the ene.

center of mass was assumed. These ralculated result re represent the measured values quite anc. curatels. The yedd appears 10 he antisymetric about $(M)^{\circ}$ and ehanges hy anly 7.7 , in suring from (k) (a) $13^{\circ}$.

Far the actual spectrum metistiremoms from the oralloy sphere. a tritium gas coll was mommert on at insulated snout at the end of the $\left(0^{\circ}\right.$ beam lube of the fandem accelerater. The hypudermic fillines trebe wis eronnected throwerh a ceramic insulator (a) il uranium furnace containing approximallely $1011 \mathrm{~cm}$ " of tritium trapped in the umanium. This furnace was heated to relase the tritium info the gas rell. Also, conmected fo the hypodermic lubing was a piezoresistive transducer with dignal readoul lin 
measuring gas pressure. The pressure could be reproduced to $1 \%$ using this device, and variations of $0.1 \%$; during a run could be noted.

\section{MULTIPLYING ASSEMBLY}

The hollow oralloy sphere designated MA-0 is detailed in LASL, drawings 32Y-20935-C4, 5. and 8. and is shown schematically in Fig. 7. The sphere is parted along a diametrical plane, and in this plane there are three holes which accommodate parts of the target for the Cockcroft-Walton accelerator. Fach half of the sphere is composed of three hemispherical shells which fit together to form a hollow sphere with an inner radius of $2.225 \mathrm{~cm}$, an outer radius of $7.799 \mathrm{~cm}$, and a mass of $37.764 \mathrm{~kg}$.

For the spectrum measurements, the hemispheres were positioned with the largest radial hole around the insulated snout and with the gas cell in the center of the spherical cavity. The hypodermic filling tube passed through the radial hole in the sphere at right angles to the largest one. Electrical tape was used to ensure that the sphere did not touch any portion of the target, which would have shorted out the current integrating system. A pneumatic lif: mechanism detailed in LASL drawing 70Y-157044D1 1.5 and shown in Fig. 8 was used to support ar.d assemb!e the two hemispheres. Also shown in Fij. 8 are the two cadmium clad hemispheres positioned aroind the tritium target with the lift mechanism in the down position.
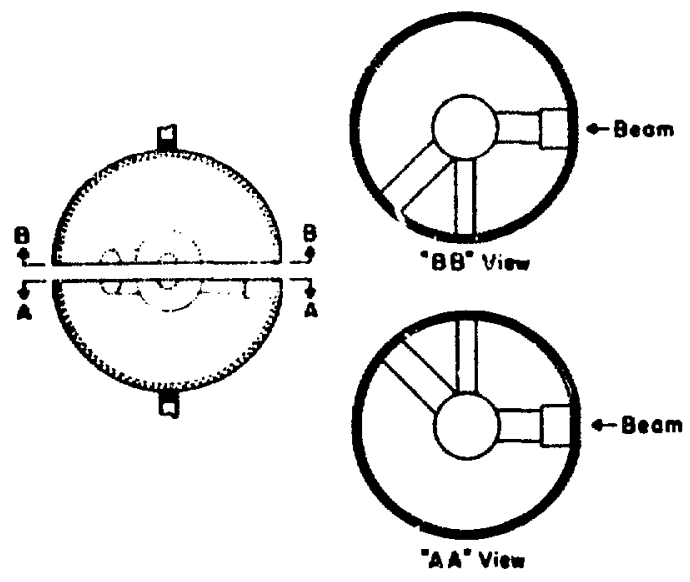

Fig. 7.

Schematic of the $37.764-\mathrm{kg}$ oralloy sphere. The sphere is parted along a diametrical plane and the three holes in this plane are to accommodate parts of the target for the CockcroftWalton accelerator.

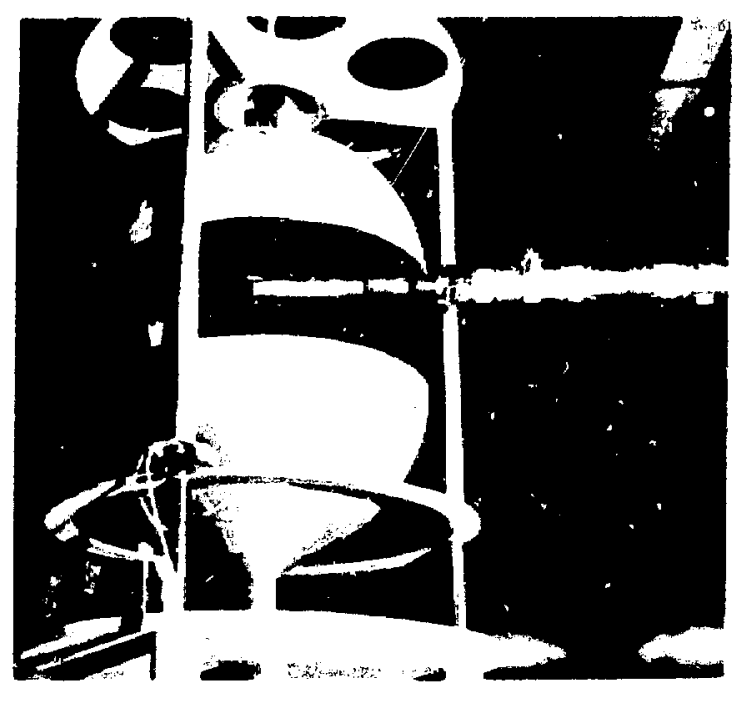

Fig. 8.

ikotograph showing the oralloy sphere and the pneumatic lift inechanism. The top hemisphere is suspended in place, and the bot. tum hemisphere is lowered to show the tritium gas cell in the central cavity.

\section{NEUTRON DETECTOR AND ELEC- TRONICS}

Neutmons were detected with a $2.54-\mathrm{ctn}$-thick by 12.70-cm.diam NE.213 liquid scintillator mounted on an RCA-8854 photomultiplier tube. A schematic of the detailed elect mnics is shown in Fig. 9. The fast output (anode) from the tube base was shaped by a constant fraction discriminator to provide start signals from the detector. Stop signals were provided by a delayed pulse obtained from a capacitative beam pickoff. Each start-stop pair was converted to digital time information using a $62.5-\mathrm{MHz}$. EG\&G clock with a timing resolution of $0.125 \mathrm{~ns}$. This time information was stored in the SDS.930 on-line computer with 8-ns channel widths. By using the different rise-time characteristics of the NE-213 scintillator for neutrons and gamma rays, ${ }^{6}$ a tag pulse was generated for each detector pulse. These tags were used to route the neutron and gamma-ray TOF spectra to different portions of memory in the computer. At the end of each run the spectra in the computer were written onto magnetic tape for later analysis using the CDC- 6600 computer. 


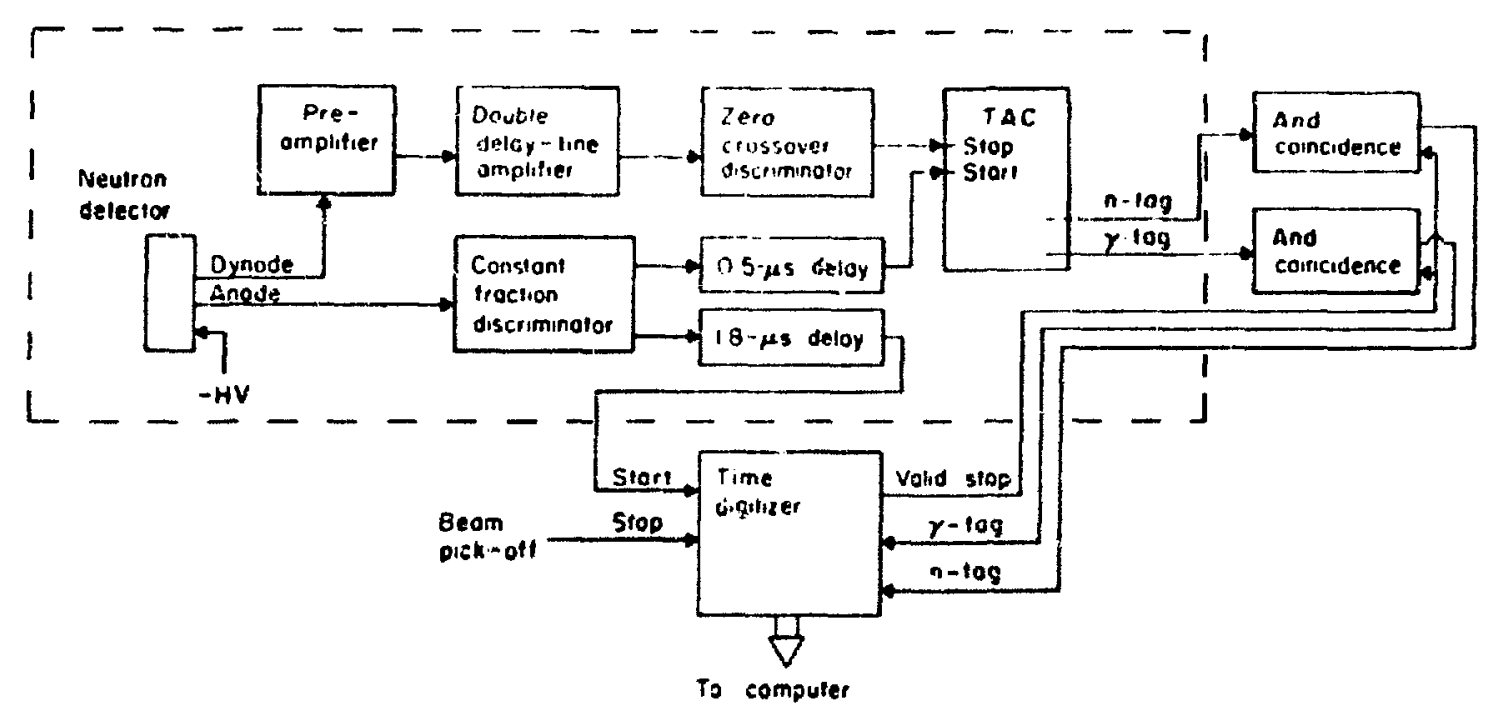

Fix. 9 .

Elotronices setup used in the me'asurement of the spectrum from the orallon sphere. The

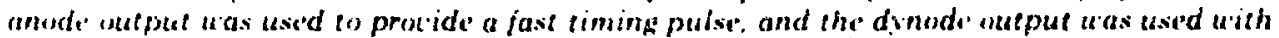

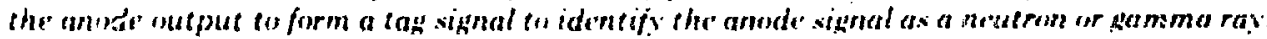
This distinguishing signal came from the sime tu-amplitude com erter (TAC') and uriginated

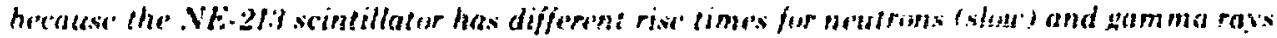

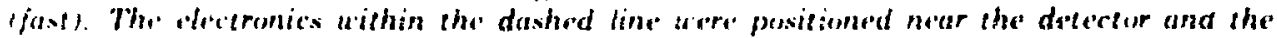
remainder "ure' he'ar the computer.

To unfold the spece rum shape from the mensurted numirer of counts. it is necessirty to know the e.t. ficiency of the detector as a function of enerery. The. shape of this curve withesu n.? discrimiantion, an be calculated because it depends on the neutronprotun cross section. the detector thickness, and the detector bias or low-energy threshold. Hewever. the effectiveness of the a, discrimination is a function of energy; therefore the efficiency must be determined experimentally.

Saturation effects in the n.y discrimination circuit cause some high-energy neul rons $t 0$ be lagked is gamma rays. thereby limiting the dynamic range of the syst (em. The pulse height out put of XE. 2 ti3 is not linear in neut ron energy. " and the energy range from 0.2 to $17 \mathrm{MeV}$ represents a dinamic range of approximately 60). Therefore, this eneray range was covered in two steps by using two different high voltages on the photomultiplier tube. A bias of $-2100) V$ was used to cover the ranue from ajoproximately $1 .+1017.0 \mathrm{MeV}$ and a hias of $-26(0) \mathrm{V}$ wasi used for the range $<0.2$ in $-5.0 \mathrm{MeV}$. The relative deteftor efficiency was measured at both voltages over the above energy ranges.

This efficiency was measured using monoenergetic neutrons produced hy charged particle reaction.:

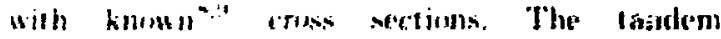
arcelerater porenided momenergetic neutross with

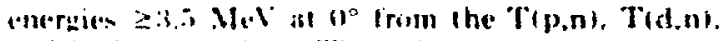
and fldinl reations. The efficheney measurements at these nest ren conetgides invilved anly determining the relative mumber an antme in the neatrass peak

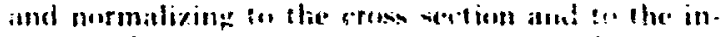
serraterl beam current after correnting for dead leme

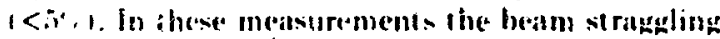
in the 11:6i.mo/em " molvhdenum eni rance windess to the gis tarket was smatl. For neut ron energies heden bin MAd. the efficiency was measured using the sertical atcelerater. The two sets of metsurements were normalized in the owerlap regun

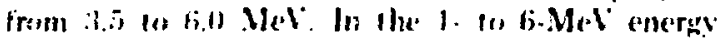
range, the T(p),nt reatction at $0^{\circ}$ was used as a monecenergetic neutron source. Neturoms below 1 Mel were obluaned from the Tip.ul reaction at anglen of ther than $0^{\circ}$. The deteder edficienes was ex. tricted frum these measurenents by normalizing the counts in the neutron peak to the integrated current and to the TIp.n: cross section at the appropriate angle. In the measurements at low incident energy there was a considerable spread in the neutron energy due both to straggling in the molybdenum entrance foil and iritium gas, and to 
kinematic broadening. These effects introduced uncertaint ies in the efficiency measurements, and they were amplified by the rapidly changing detector efliciency near threshold. where small changes in the energy or drifts in the electronics introduce large errors in efficiency.

Figure 10 shows plots of the relative efficiency curves at the two photomultiplier high voltages used in the spectra measurements. "'he efficiency near threshold showed small drifts during the time required to complete the spectra measurements (several months). For this and the above-mentioned reasons. larger errors have been assigned to these low-energy points. (See Sec. VIll.)

\section{FIIGHT TUBE}

The llight path for measuring the spectrum using TOF techniques is $38.87 \mathrm{~m}$ from the center of the gas cell to the enter of the detector. An evacuated 30.5. $\mathrm{cm} \cdot \mathrm{diam}$ iron pipe covers approximately $29 \mathrm{~m}$. whereas air fills the remaining distance. The win-

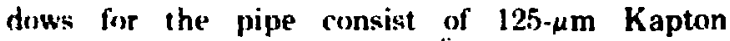
$\left.1{ }^{16} \mathrm{H}_{4} \mathrm{O}_{4} \mathrm{~N}_{2}, 0=1.42 \mathrm{gcm}^{-3}\right)$ : Figure 11 is a photograph of one end of the iron pipe showing the window.

Two 1.2-m-long collimators were installed in the mipe. These collimators consist of $2.5-\mathrm{cm}$-wall iron pipes. with 15.24 - and $16.51 \mathrm{~cm}$ inside diameters. The smaller collimator. located approximately $7.3 \mathrm{~m}$

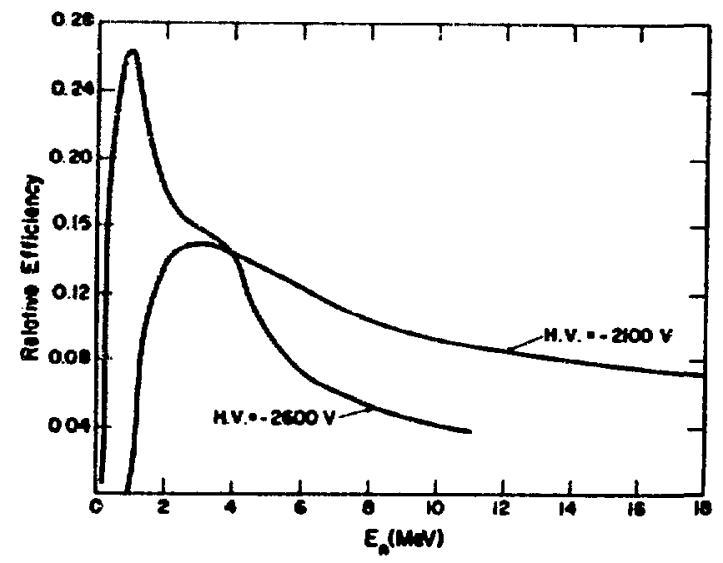

Fig. 10.

Plots showing the relative efficiency of the defector as a function of neutron energy. These efficiancies were measured at plotomultiplier volt ages of -2100 and $-2600 \mathrm{~V}$ and correspond to thresholds of 0.85 and $0.15 \mathrm{MeV}$, respectively.

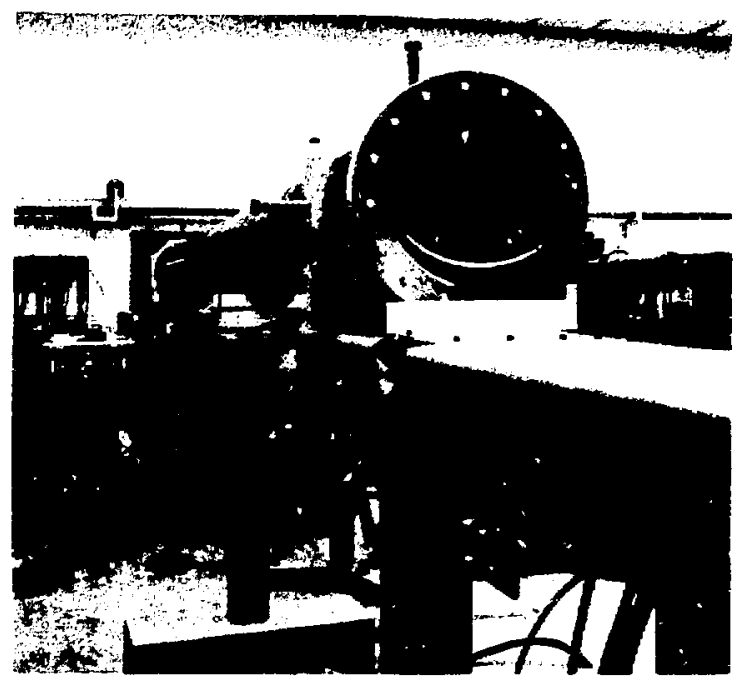

Fig. 11 .

Photograph showing the end of the evacuated flight pipe nearer the detector with a stretched 125.um Kapton window. The vacuum in the pip. was maintained at less than $60 \times 10^{-3}$ torr.

from the source, defined the viewing area for the $12.70-\mathrm{cm}$-diam detector. Each collimator was located where the flight tube passes through a $0.9-\mathrm{m}$ thick concrete wall. The hole in the wall around the pipe was filled with lead, iron, and polyethylene shielding material. A schematic of the flight path is shown in Fig. 12. The entire pipe was aligned to better than $3 \mathrm{~mm}$ using a laser, and tha collimators were positioned to an accuracy of $1 \mathrm{~mm}$.

At the end of the flight tube, the detector and associated electronics were housed in a portable building (Fig. 13). The beam enters the building through a $125-\mu \mathrm{m}$-thick clear-poiystyrene window. A traveling telescope mounted about $2 \mathrm{~m}$ behind the detector was used to locate the center of the beam. With the detector centered within $1 \mathrm{~mm}$ of the beam center, the collimating system allowed the detector to view a circular source with a diameter only $3 \mathrm{~mm}$ greater than that of the oralloy sphere.

\section{EXPERIMENTAL PROCEDURE}

Three separate sets of measurements of the neutron spectrum from the oralloy sphere were performed on May 7, June 11, and August 29, 1974. For each set of measurements the two oralloy 


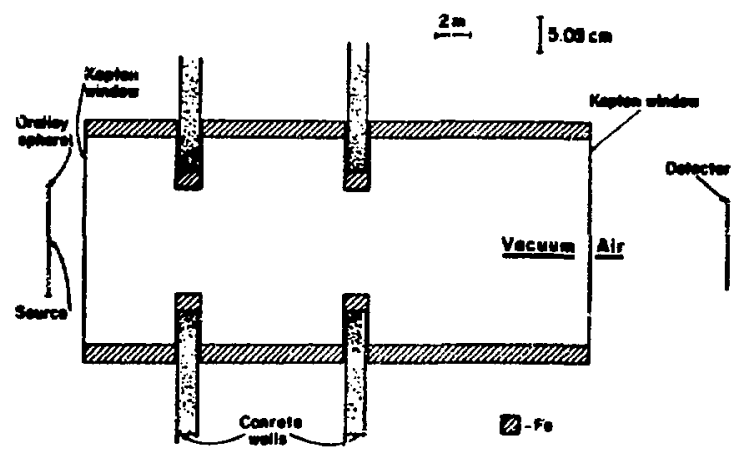

Fig. 12.

Flight path from the source to the detector showing the collimating system for limiting the detector field of view. Notice the scale differences in the two directions.

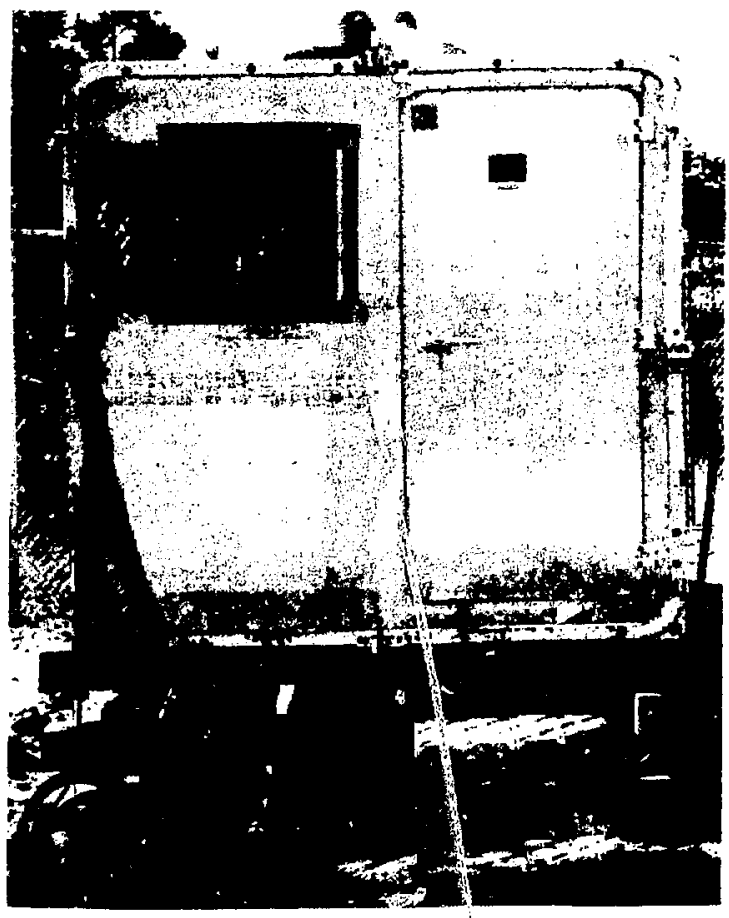

Fig. 13.

Portable building containing the detector (in the window) and the electronics within the dashed line of Fig. 9. Also shown at the left are the signal cables from the detector to the computer area. hemispheres were transpurted in separate containers from the vault at I.ASI. (iroup A-2 to I.ASI, (iroup P-9. Each hemispt sre was rezeoved from its con tainer, in the presence of ar $H$-i Division monitor. and was fitted inside a $0.75 \cdot \mathrm{mm} \cdot \mathrm{thick}$ cadmium hemisheil, which was used as a shield frum therma! room-return neutrons.

Before beginning each series of runs. the low energy threshold and n.r discrimination properties.

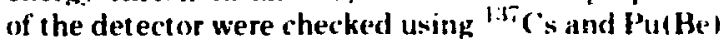
sources, respectively. The target cell was filled with helium to check for pressure stability whillo the beam was being tuned on target. Affer making these checks, the gas cell was lilled to 0.216 Mal'a haluge t:i2 psig) of tritium by heating the uranium furrace. and a spectrum of the bare source was recurded for a specified integrated current of incident deuterons. This run was also used to assure that the elect ronies were working properly.

The sphere was then pesitioned around the target using the assembly shown previensily. As a precau. tion, when the two heinisplieres were being assemb! ed. the gamma-rav activity was monitured in dotectors with an autible alarn. The parting plane of she sphere was tipped about $1^{\circ}$ from horizontal so that it was not in line with the detector. In the Misy 7 runs. the sphere was not tilted and a $0.5 . \mathrm{mm}$ separation between the two hemispheres was responsible for an anomalously large number of source netutrons. reaching the detector. However, the other pertion al the spectrum was not affected by the separation. In the other runs, the spgaration between the hemispheres was less than $0.05 \mathrm{~mm}$.

For each set of runs, several sipectra were recorded with and without the uralloy sphere surrounding the tritium-filled gas cell. These runs provicled a measurement of the transmission of $14-\mathrm{MeV}$ neutrons, as well as a measure of the shape of th: spectrum from the sphere. The gas cell was then evacuated and illed with helium gas 10 a pressure of $0.218 \mathrm{MPa}$ gauge, and the time-of-flight measurements were repeated with and without the sphere. These spectra were used to measure the neutrons associated with the $\operatorname{Mo}(d, n)$ and other background reactions. For the May 7 and August 29 measurements, spectra were recorded with detertor thresholds of approximately 0.15 and $0.85 \mathrm{Me}:$. For the June 11 measurements, spectra were recorded using only the $0.85-\mathrm{MeV}$ threshold; however, five pairs of sphere-on and sphere-off runs were recordeo to obtain an accurate measure of the transmission for 14-MeV neutrons. These five pairs of runs repeated within statistics, indicating accurate current integration and reproducibility in positioning the sphere. 


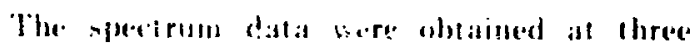

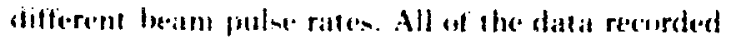

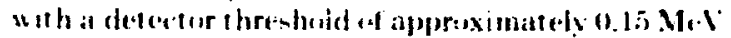

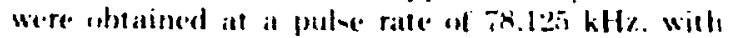

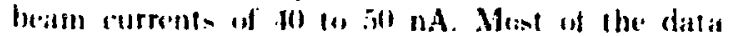
recorded with a deteder threshold of abeut athi Me. were abtained at a polse rate of 0.3125 . Mh

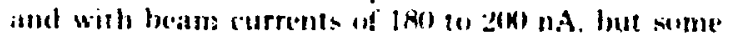
runs with this threshold were obstined at the lower pulac ratte. 'The datta le ded tudesermine the iratsma is.

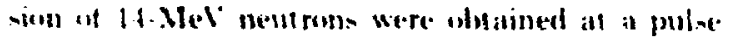

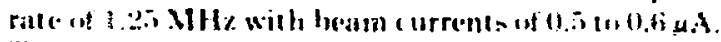

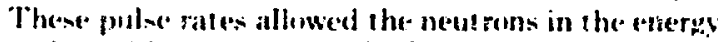

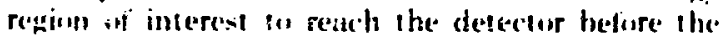
next beam pulse.

\section{DATA RHUE ("HOX ANI) RESLITS}

Figure If shew- typical smetra recerded with the sphere in place and with the esll filled with trition and helium. These raw data in counts per chanmed were redueded to ment roms/M. M.

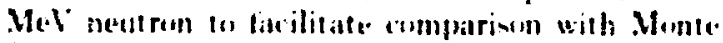

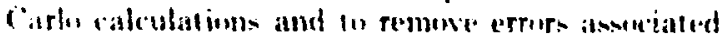

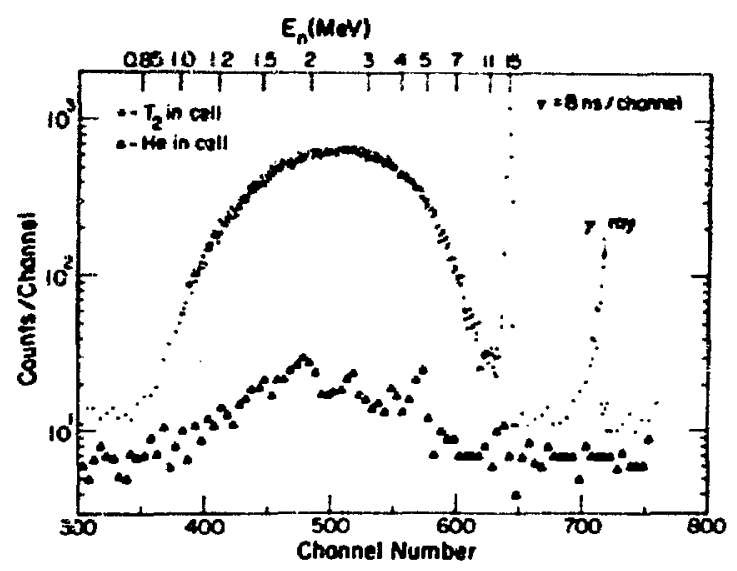

Fig. 11.

I"Wts of the rall data in counts per channel as a function of channel obtaince with the sphere in place and with tritium (-) and helium (A) in the rell. These spectra were recorded with a defeceur threshold of $0.85 \mathrm{MeV}$ with channel uidths of $8 \mathrm{~ns}$. The integrated current for each spectrum was $10^{5}{ }_{\mu} C$, but the holium run used a slightly larger beam current and thus a shorter time. For this reason, the time. indepondent background is less than in the tritium run. The neutron energy in $\mathrm{MeV}$ is given along the top of the graph. with uncertaintes an the absolute detector efficien er. Thio reduction was accomplinhed in the following manner. If $X_{1}$ ifidf is the number of nestrenn-

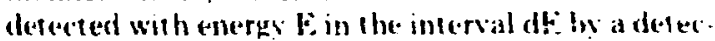
tor of area $A$ at the end of a tlipht path of length during the $i^{\text {th }}$ run for $\left(* \mu C^{*}\right.$. Then the number of source neutrons from an isotropic source fer microcoulomb in the eneres interval dF is given by

$$
n_{i}(E) d E=\frac{4 \pi \delta^{2} b_{i}(E) d E}{\delta C_{i} E_{b}(E)}
$$

where en 1 F, is the detector efliciency tor a threshold h. Thus the nutuber af 14-Mel source newtion- per Mel from a bare isul repic sougree is given by

$$
r_{i}(E)=\frac{4 \pi l^{2}}{i c_{i}} \frac{1}{E_{b}(i 4)} \sum_{L_{i}+s} N_{i}(E),
$$

where the sum is aner the neutrome in the $14-\mathrm{Mel}$ puak atd where the averase effeciency for $14-M$. meutrons s,llfl has been remused from the summalion. For an anisol rupic source which is an. tiolmmelric abust $(k)^{c}$ with a(t) representing the rati* of the number of neutrons per steradian at an "nule " Io tho average tamber emitted per steradian. the number of source 14-Mel neutrons is

$$
n_{i}(E)=\frac{4 \pi R^{2}}{A c_{i} a(\theta)} \frac{1}{\bar{E}_{b}(24)} \sum_{14 \cdot s} N_{i}(E) .
$$

For the present surese and detector. $n=0^{\circ}$ and " $\left(10^{\circ}\right)=1.0 \%$. Then for a run with the oralloy sphere in place. the number of neutrons at the detector per Mis.(cm² persisurce 14-Mel'neutrom is

$$
\begin{aligned}
n_{j}(E) & =\frac{N_{j}(E) /\left[\varepsilon_{b}(E) c_{j} A\right]}{4 \pi l^{2} \sum_{14 ' s} N_{i}(E) /\left[E c_{j} a\left(0^{\circ}\right) \bar{\varepsilon}_{b}(1 ;)\right]} \\
& =\frac{N_{j}(E) a\left(0^{\circ}\right)}{\frac{c_{j}}{c_{i}} 4 \pi \ell^{2} \sum_{14 \cdot s} N_{i}(E) \frac{\bar{\varepsilon}_{b}(E)}{\bar{\varepsilon}_{b}(14)}}
\end{aligned}
$$


where $N_{i}(F)$ is the number of detected neut rons per $\mathrm{MeV}$ for $\mathrm{C}_{\mathrm{j}} \mu \mathrm{C}$. This number is obtained from $\mathrm{N}_{\mathrm{j}}(\mathrm{k})$. the net counts per channel in chainnel $k$, using the relation

$$
N_{j}(E)=\frac{d k}{d E} \quad N_{j}(k)=\frac{1}{\tau} \frac{t}{2 E} N_{j}(k) .
$$

where $t$ is the flight time for neutrons of energy $F$ and $r$ is the time per channel. The flight time and relativistically correct energy are calculated using the relations

$$
\tau=\tau\left(\left|k-k_{Y}\right|+A\right)
$$

and

$E=939.505\left[\left\{1-\left.\left|A /\left(A+\left|k-k_{Y}\right|\right)\right|^{2}\right|^{-1 / 2}-1\right]\right.$,

where the gamma-ray flight time is $\mathrm{A}=3.33356 \mathrm{~d} / \mathrm{\tau}$ and $k$, is the gamma-ray chammel.

'lhe number of source neutrons

$$
\sum_{14 \%} N_{i}(\mathrm{E})
$$

was obyained from the runs taken with the sphere removed and with tritium in the cell by summing the counts above a background obtained from a linear interpolation under the peak.

For the $j^{\text {th }}$ run with the sphere in place, the net number of counts in the $k^{\text {ih }}$ channel $N_{j}(k)$ was obtained from the raw data in the following manner. First, the raw data were corrected for "dead time" by multiplying the counts in each channel by the ratio of the toral mumber of start pulses to the number of start-stop pairs accepted by the computer. Then. two types of background were subtracted from the spectrum. A time-independent background not associated with the beam pulse was obtaired for each channel by averaging many channels in the flat portion of the spectrum preceding the gamma-ray bursts. This background was obtained to an accuracy of a few percent and wals le'ss than 54, of the counts per channel in most (ases. A time-dependent background was obtained from the runs with helium in the cell and with the sphere in place. These spectra were corrected for dead time and time-independent backsround, normalized to the integrated current, and subtracted channel by channel from the runs with tritium in the cell. This background was 1 to $5^{\prime \prime}$. of the total number of counts per channel.

Sample listings of the raw data obtained on August 29, 1974, using a detector threshold of 0.85 $\mathrm{MeV}$ with tritium or helium in the cell are given in Tables I and II, respectively. Table III lists the results obtained from these data for every fifth channel. The channel number and energy are given in columns 1 and 2. Column 3 gives the net spect rum after dead time corrections, and column 4 lists efficiency-corrected values for the neutrons/MeV$\mathrm{cm}^{2} /$ source neutron at the detector. The statistical error associated with cach channel is given in column 5.

These data were then averaged over the energy bins in Table IV for comparison with Monte Carlo calculations. This averaging was performed by finding the net number of neutrons per square centimeter for each energy bin and then dividing this sum by the energy bin width to give neut rons/ $\mathrm{MeV} / \mathrm{cm}^{2}$. The energies listed in Table IV are the upper bounded for each bin and were chosen. generally, to cover a wide simugh energy to give good statistics. The bin boundary at $13.29 \mathrm{MeV}$ was chosen because this represents the low energy point tor the direct source neutrons in the $14-\mathrm{MeV}$ peak. These are the neutrons that come out at back angles and scatter into the detector. After averaging, the statistical errors were reduced substantially, and. when combined with the errors associated with background subtraction, were less than $1 \%$, in the energy interval 0.3 to $6.0 \mathrm{MeV}$. In the energy interval below $0.3 \mathrm{MeV}$ and from 6.0 to $13.29 \mathrm{MeV}$, the largest error from these two sources occurs at 13.29 MoV and is about $10 \%$. In the peak at $14 \mathrm{MeV}$, the combined statistical error and that associated with background subtraction is about $4^{\prime} i$. Over most of the energy range, the largest errors in the experimental results are associated with uncertainty in the detector efficiency. These efficiency-associated errors are 5", in the interval from 2 to $13.29 \mathrm{M} \cdot \mathrm{V}$. $10^{\circ}$, in the interval from 1 to $2 \mathrm{MeV}$, and $15^{\circ}$, below $1 \mathrm{MeV}$. At $14 \mathrm{MeV}$ the detector efficiency introduces no error.

The data obtained with a detector bias of ap)proximately $0.15 \mathrm{MoV}$ were normalized to the dat a obtained at a bias of approximat ely $0.85 \mathrm{MoV}$ in the enorgy region from 1.5 to $5.0 \mathrm{MoV}$. The composite spect rum obtained from all the data is presented in 
TABLE

RAW DATA OBTAINED WITH TRITIUM IN CHLL.

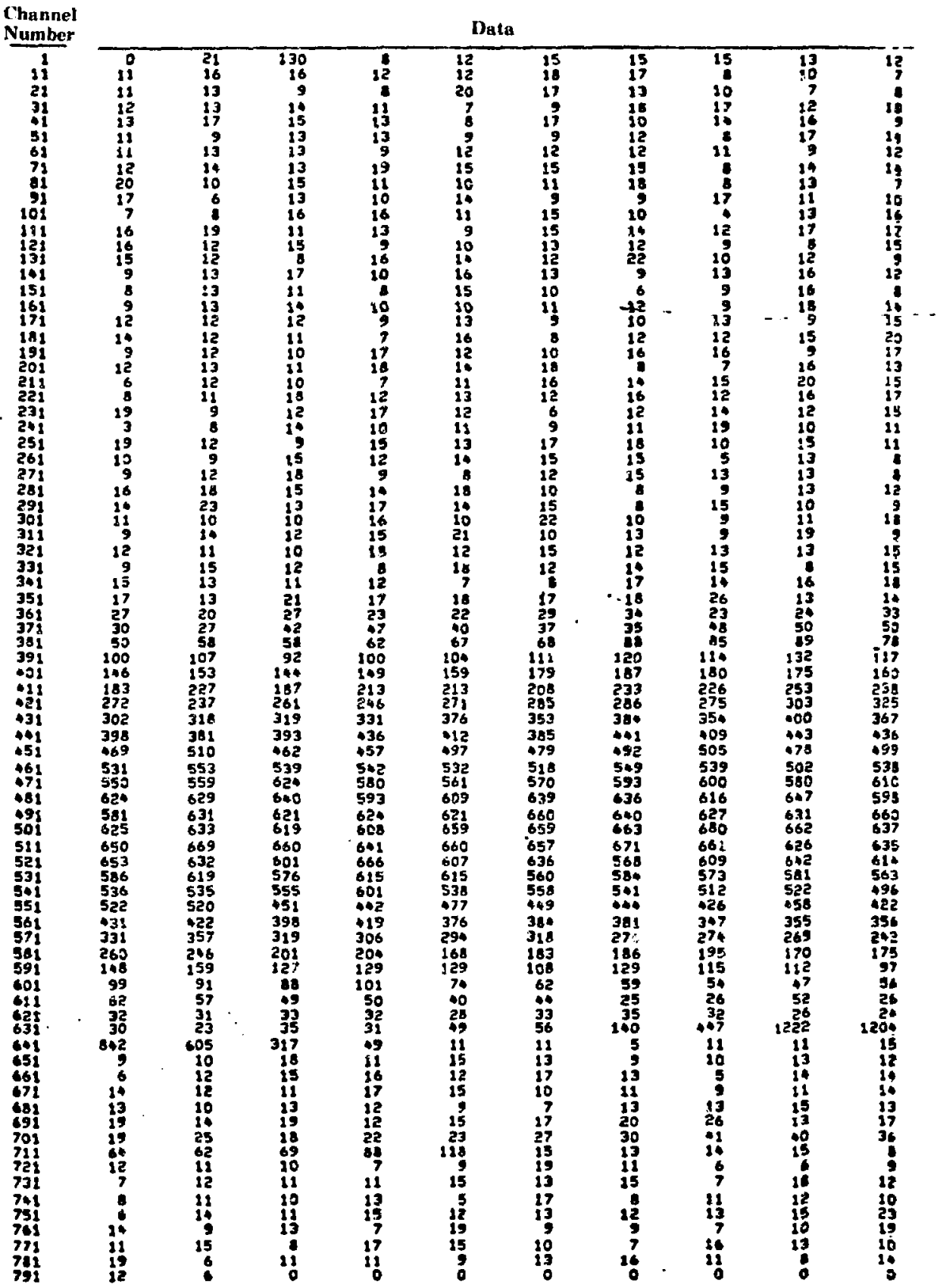


TABLE II

RAW DATA OBTAINED WITH HELIUM IN CELI,

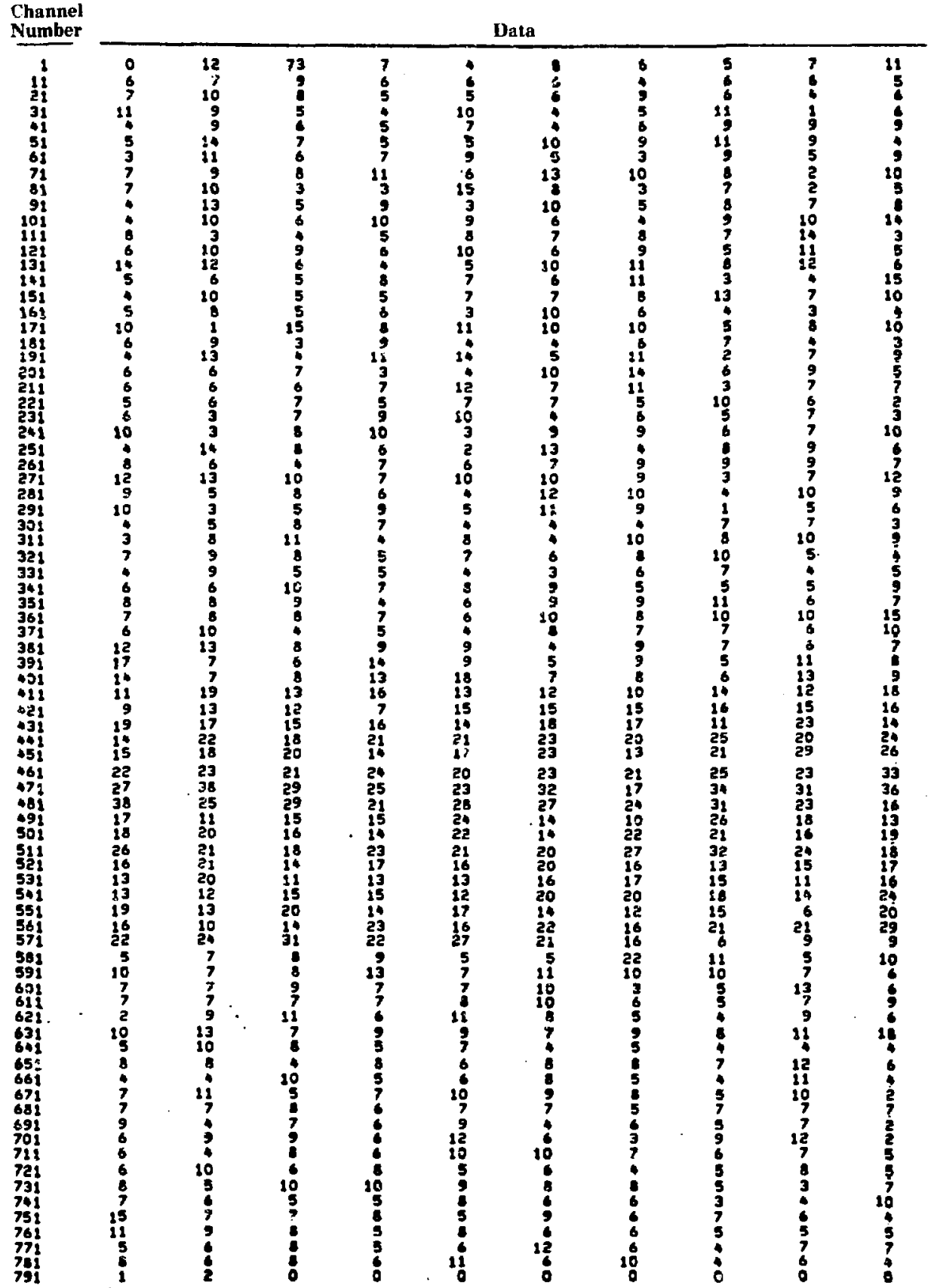


TABLE III

REDUCED DATA FROM TABLES I AND II

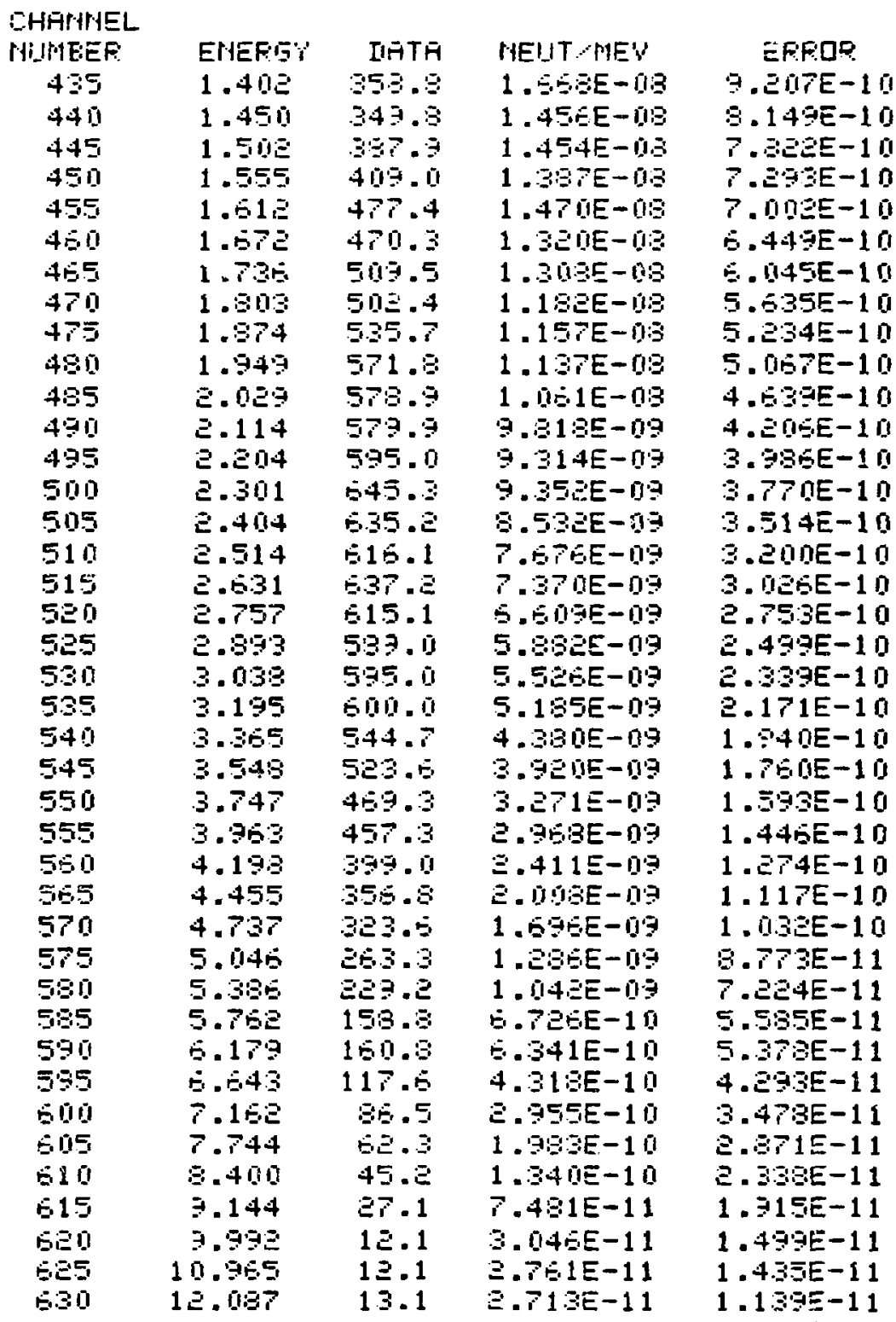


TABLE IV

\section{MEASURED NEUTRON SPECTRUM FROM ORALLOY SPHERE}

\begin{tabular}{|c|c|c|}
\hline$\underset{(\mathbf{M e V})}{\mathbf{E}_{\mathbf{n}} \mathbf{a}^{2}}$ & $\begin{array}{l}\text { Neutrons } / \mathrm{MeV}-\mathrm{cm}^{2} / \text { Source } \\
\text { Neutron at the } \\
\text { Detector } \times 10^{-9}\end{array}$ & $\begin{array}{c}\text { Error } \\
(\%)\end{array}$ \\
\hline 16.0 & 0.98 & 4 \\
\hline $1: 3.29$ & 0.042 & 15 \\
\hline 10.0 & 0.089 & 12 \\
\hline 8.0 & 0.358 & 8 \\
\hline 6.0 & 1.60 & 6 \\
\hline 4.0 & 4.21 & 5 \\
\hline 3.0 & 6.99 & 5 \\
\hline 2.5 & 9.6 & 5 \\
\hline 2.0 & 11.8 & 10 \\
\hline 1.8 & 13.3 & 10 \\
\hline 1.6 & 15.3 & 10 \\
\hline 1.4 & 17.1 & 10 \\
\hline 1.2 & 19.9 & 10 \\
\hline 1.0 & 21.1 & 15 \\
\hline 0.9 & 23.4 & 15 \\
\hline 0.8 & 25.4 & 15 \\
\hline 0.7 & 28.5 & 15 \\
\hline 0.6 & 31.6 & 15 \\
\hline 0.5 & 32.6 & 15 \\
\hline 0.4 & 31.1 & 16 \\
\hline 0.3 & 29.4 & 20 \\
\hline 0.2 & 23.6 & 25 \\
\hline 0.18 & ... & $\ldots$ \\
\hline
\end{tabular}

${ }^{a}$ Upper boundary of energy bin.

Table IV, along with the total experimental uncertainty for each energy bin. This uncertainty was obtained by simply adding the statistical uncertainty in each energy bin to the uncertainty from the detector effíciency.

\section{COMPARISON WITH MONTE CARI,O CALCULATIONS}

Monte Carlo calculations were performed by LASL's Theoretical Design Division with the code MC. . " The detailed geometry shown in Fig. 12 was used in these calculations with a point detector positioned at $0^{\circ}$ to the beam at a distance of $38.47 \mathrm{~m}$ fro;n the source. The effect of the collimating system and concrete walls was simulated by setting the ce!l importance ts zero for those cells outside the volume defined by a $30.5-\mathrm{cm}$-diam cylinder from the source to the detector. When a neutron was scattered into this volume outside the cylinder, its weight was set to zero and its path was no longer followed.

The measured energy and yield as a function of angle (Fig. 6) were used in the source subroutine for these calculations. The sphere geometry used in the code is shown in Fig. 7. Neutrons per square centimeter were tallied in the energy bins of Table IV and then divided by the energy bin width to give neut rons/MeV-cm 2 /source neutron. Statistical errors of ' $2 " ;$ or less were acquired in several hours of computer time for most energy bins, with the largest error of approximately 5 "; occurring for the 10- to 13.29- MeV bin.

Cross-section sets from LLL and INDF/B-IV were used to calculate the spectrum. These calculated results are presented in Table V. Figure 15 shows a comparison of the experimental results with the calculated results using the two cross-section sets. The experimental results are plotted at the midpoint of each energy bin and the calculated results are shown as curves from the midpoint of one bin to the next. Both sets of results are in reasonable agree. ment with the experimental results. However, the ENDF/B.IV cross-section set does provide much better agreement, and in the region from 1 to $6 \mathrm{MeV}$ the aureement is excellent. Both cross-section sets appear to predict a harder spectrum above $6 \mathrm{MeV}$ than is cobserved. and the worst agreement is in the 10. - to $13.29-\mathrm{MeV}$ hin where the statistical errors, both for experimental and calculational results, are the larsest. Future experiments are planned to cover more fully the region below a tew hundred $\mathrm{keV}$.

\section{REFERENCES}

1. R. E. Hunter, Los Alamos Scientific Laboratory. private communication, March 4. 1974.

2. C. E. Ragan, Lus Alamos Scientific Laboratory. private communication, Sept. 27, 1974.

3. Lema Stewart and Gerald $M$. Hale, "The Tr(d.n $)^{4} H_{e}$ and T(t.2n) Cross Sections at low Energies." Los Alamos Scientific Laboratory report I.A-58:28-MS (Jan. 1975).

4. Iohn D. Seagrave. "D(d.n)HF":3 and T(d,n)He Veutron sonrce Handhook," Ios Alamus Scrientific Libburatory report LA.MSS-2162 (Xox. 1957). 
TABLE V

\section{CALCULATED NEUTRON SPECTRUM FROM ORALLOY SPHERE}

\begin{tabular}{|c|c|c|}
\hline \multirow[b]{2}{*}{$\underset{(\mathbf{M e V})}{\mathbf{E}_{\mathbf{n}} \mathbf{a}}$} & \multicolumn{2}{|c|}{$\begin{array}{c}\text { Neutron/MeV-cm } \mathrm{cm}^{2} / \text { Source } \\
\text { Neutron } \times 10^{-9}\end{array}$} \\
\hline & $\begin{array}{c}\text { LLL } \\
\text { Cross Sections }\end{array}$ & $\begin{array}{l}\text { ENDF/B-IV } \\
\text { Cross Sections }\end{array}$ \\
\hline 16.0 & 0.86 & 0.94 \\
\hline 13.29 & 0.044 & 0.044 \\
\hline 10.0 & 0.125 & 0.140 \\
\hline 8.0 & 0.41 & 0.48 \\
\hline 6.0 & 1.55 & 1.58 \\
\hline 4.0 & 3.7 & 4.1 \\
\hline 3.0 & 5.8 & 6.5 \\
\hline 2.5 & 7.8 & 9.1 \\
\hline 2.0 & 9.6 & 11.3 \\
\hline 1.8 & 11.0 & 13.5 \\
\hline 1.6 & $1: 3.0$ & 15.0 \\
\hline 1.4 & 15.0 & 16.5 \\
\hline 1.2 & 18.0 & 20.0 \\
\hline 1.0 & 21.5 & 21.5 \\
\hline 0.9 & 22.5 & 23.5 \\
\hline 0.8 & 25.0 & 25.5 \\
\hline 0.7 & 28.0 & 27.0 \\
\hline 0.6 & 31.5 & $29 . \bar{n}$ \\
\hline 0.5 & 34.0 & 30.5 \\
\hline 0.4 & 34.5 & 31.0 \\
\hline 0.3 & 31.5 & 27.5 \\
\hline 0.2 & & \\
\hline
\end{tabular}

a' Upper boundary of' energy bin.

5. H. V. Argo, R. F. Taschek. H. M. Agnew, A. Hemmendinger, and $W$. T. Laland, "Cross Sections of the D(T.niHe ${ }^{4}$ Reaction for 80)- in 12(Y)-kel: Tritons." Phys. Reve. 87. 612 (1952).

6. See. for example. 1. J. Taylor and .l. Kalyna. "A High Speed Pulse Shape Diseriminatur." Nucl. Instrum. Methods 88. 267119701.

7. V. V. Verbinski, W. R. Burrus, T. A. INe. W. Zohel. N. W. Hill, and R. Textor. "Calibration of an Organir Srintillatur for Neutrum spectrometry." Nucl. Instrum. Methods 65. 8 (196(i)).

8. H. Liskien and A. Pitulsen. "Neut ron Priklut. lion Cross Sections and Bnergies for the Renctions $T(p, n)^{3} H e$. D(d, $\left.n\right)^{3 / H e}$. and T(d,n)'He." Nuel. Dat a Tables 11. 5169 (1973).

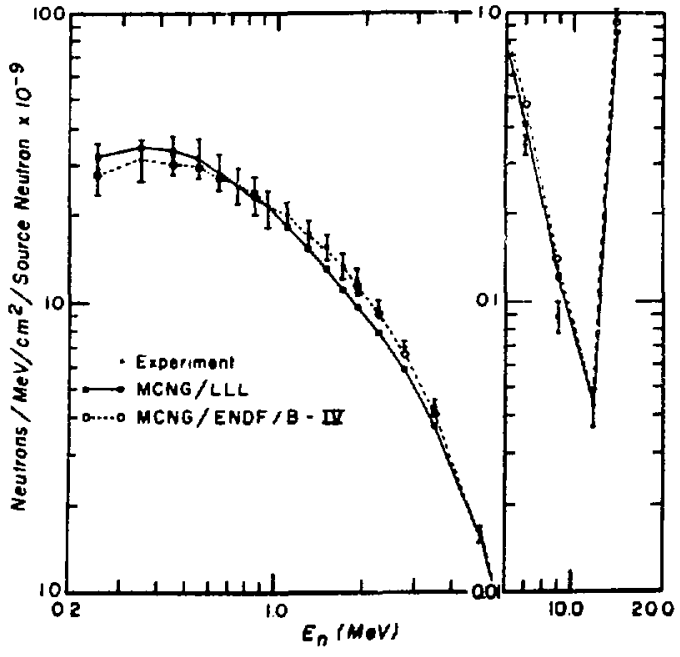

Fig. 15.

C'omparison of the experimental and calculated spectrum from the 38-kg oralloy sphere at the detector in neutrons $/ \mathrm{cm}^{2} / \mathrm{MeV} /$ source neutron. The Monte Carlo code $M C N$ was used to obtain the calculated results, and in these calculations two sets of cross sections were used-one from $L L L$ and one from the ENDF/B-IV library. The results from the ENDF/B-IV calculation are in excellent agreement with the experiment and are a substantial improvement over the calculations using the LLL, cross sections, especially in the 1- to 6$M \cdot V$ energy region.

9. M. Drosg and D. M. Drake. “Absolute Differential Cross Sections for Neutron Production by the ${ }^{2} \mathrm{H}(\mathrm{d}, n)^{3} \mathrm{He}$ Reaction with $\mathrm{E}_{\mathrm{d}}$ from 6 to $17 \mathrm{MeV}$ and by the ${ }^{3} H(p . n)^{3} H e$ Reaction with $E_{p}$ from 6 to 16 Mel." Los Alamos Scientific Laboratory report LAiT:32-MS (Der. 1974).

10. E. D. Cashwell. J. R. Neergaard. W. M. Taylor. and (i. D. Turner. "MCN: A Neutron Monte Carlo (ade." Los Alamos Scient ific Laboratory report l.A. t7isl (J)an. 1972); E. D. Cashwell. J. R. Neerzand. C. J. Everetı. H. (C. Sithrande. W. M. Taylur. and G. D). Turber. "Monte Carlo Photon Cockes: MC' and MCP." Ios Alames Scientific lahoratury report LA. \$157-MS (19)2): IR. (i. Sithrandt. "MC.N(; . Running Instructions." las Alamos Stientific l.alboraton: privale communication (1973). 